Lailatul Mustaghfiroh : Hubungan Pekerjaan Di Pabrik Rokok dan Perilaku Hidup Bersih Sehat Ibu Terhadap Kematian Bayi

IJEMC, Volume 1 No. 1, Desember $2014 \mid \mathbf{5 3}$ 
Lailatul Mustaghfiroh :Hubungan Pekerjaan Di Pabrik Rokok dan Perilaku Hidup Bersih Sehat Ibu Terhadap Kematian Bayi 
Lailatul Mustaghfiroh : Hubungan Pekerjaan Di Pabrik Rokok dan Perilaku Hidup Bersih Sehat Ibu Terhadap Kematian Bayi

IJEMC, Volume 1 No. 1, Desember $2014 \mid 55$ 


\title{
Hubungan Pekerjaan Di Pabrik Rokok danPerilaku Hidup Bersih Sehat Ibu Terhadap Kematian Bayi
}

\author{
Lailatul Mustaghfiroh, ${ }^{1}$ Jusuf Sulaeman Effendi, ${ }^{2}$ Farid Husin, ${ }^{3}$ Firman F.Wirakusuma, ${ }^{4}$ Elsa Pudji Setiawati, ${ }^{5}$ \\ Ali1Usman ${ }^{6}$ \\ ${ }^{1}$ Mahasiswa Program Studi Magister Kebidanan Fakultas Kedokteran Universitas Padjadjaran \\ ${ }^{2,4}$ Departemen Obstetri dan Ginekologi Fakultas Kedokteran Universitas Padjadjaran \\ ${ }^{3}$ Departemen Obstetri dan Ginekologi Fakultas Kedokteran Universitas Padjadjaran \\ ${ }^{5}$ Departemen Ilmu Kesehatan Masyarakat Fakultas Kedokteran Universitas Padjadjaran \\ ${ }^{6}$ Departemen Ilmu Kesehatan Anak Fakultas Kedokteran Universitas Padjadjaran
}

\begin{abstract}
Abstrak
Angka Kematian Bayi (AKB) di Indonesia cenderung meningkat.Faktor risiko masa neonatal umumnya disebabkan oleh kejadian pranatal, intranatal, dan tepat setelah lahir, sedangkan masa pascaneonatal dipengaruhi oleh lingkungan bayi.Salah satu upaya untuk menurunkan AKB adalah tindakan preventif terhadap faktor risiko kematian bayi tersebut.Tujuan penelitian adalah untuk menganalisis hubungan pekerjaan di pabrik rokok dan Perilaku Hidup Bersih Sehat (PHBS) ibu terhadap kematian bayi.Rancangan penelitian menggunakan analitik komparatif dengan pendekatan kasus kontrol.Subjek penelitian adalah 60 ibu yang bayinya meninggal sebagai kelompok kasus dan 60 ibu yang bayinya sudah berulang tahun pada saat dilakukan penelitian sebagai kelompok kontrol.Karakteristik demografi dan indikator PHBS ibu diketahui menggunakan kuesioner.Analisis statistik menggunakan uji chi kuadrat.Hasil penelitian tidak terdapat hubungan bermakna antara pekerjaan di Pabrik Rokok dan PHBS ibu terhadap kematian bayi $(\mathrm{p}>0,05)$. Interaksi antara pekerjaan di Pabrik Rokok dan sikap positif mengenai PHBS merupakan faktor risiko paling dominan terhadap kematian bayi dengan OR 2,80 (IK 95\%=0,64-13,07).Simpulan tidak terdapat hubungan pekerjaan di Pabrik Rokok dan PHBS ibu terhadap kematian bayi. Ibu yang bekerja di Pabrik Rokok dan memiliki sikap positif mengenai PHBS merupakan faktor risiko terjadinya Bayi Berat Lahir Rendah (BBLR), asfiksia neonatorum, kelainan kongeital, infeksi, dan diare sebagai penyebab langsung kematian bayi.
\end{abstract}

Kata kunci: Kematian bayi, pekerjaan di pabrik rokok, PHBS ibu

Korespondensi : Jl.Jepara Kudus KM. 24 Mayong Jepara, mobile 02914256657/ HP 081325173022, e-mail laila_robin@yahoo.co.id 


\title{
Relation Of Cigarette Company Employment And The Health Clean Life Behavior Of Mother's With Infant Mortality
}

\begin{abstract}
Infant Mortality Rate (IMR) in Indonesia tends to be increased. Risk factors of infant mortality in neonatal period most commonly caused by prenatal events and the current events after birth/birth process, while in the post neonatal period is more influenced by the environment. One of the efforts to reduce the IMR is by doing preventive actions toward the infant mortality risk factors. The purpose of this study was to association of cigarette company employment and the Healthy and Clean Life Behaviour (HCLB) of mother's with infant mortality. The design was conducted a comparative analytical approach to case control. The subject of this study is 60 mothers whose the babies were died as a case group and 60 mothers who gave birth in 2012 and has been birthday at the time of the study as a control group. The data about infant mortality is taken from the report of the District Health Department and Primary Health Center. Demographic characteristics of the mother and the mother is knowed HCLB by using questionnaires. Statistical analysis by using chi square test. The results showed that there were no association of cigarette company employment and the HCLB of mother's with infant mortality ( $>0.05)$. Interaction between cigarette company employment and have a possitive attitude of HCLB is a risk factor for the incidence of infant mortality with OR value 2,80 (CI 95\%=0,64-13,07). As conclusion there is no association of cigarette company employment and the HCLB of mother's with infant mortality. The mother's who get work in the cigarette company and have a negative attitude of HCLB is a risk factor caused low birth weight, asphixia neonatorum, congenital disorder, infection, and diarrhoe as direct causes of infant mortality.
\end{abstract}

Keywords : Infant mortality, cigarette company employment, maternal HCLB 


\section{Pendahuluan}

Angka Kematian Bayi (AKB) yang meliputi Angka Kematian Neonatal (AKN) dan Angka Kematian Pascaneonatal (AKPN) merupakan indikator status sosioekonomi dan kemampuan pelayanan kesehatan suatu negara karena mencerminkan status kesehatan ibu dan anak saat kehamilan dan proses kelahiran. ${ }^{1}$ Angka kematian bayi adalah jumlah kematian bayi usia kurang dari 1 tahun per 1000 kelahiran hidup pada periode waktu tertentu. ${ }^{1-3}$ Millennium Development Goals (MDGs) tahun 2015 menargetkan AKB turun menjadi 23/1000 kelahiran hidup. Angka Kematian Bayi di Kabupaten Kudus memang kecil, berada di bawah target MDGs, Nasional, maupun Provinsi namun AKB di Kabupaten Kudus terjadi kecenderungan peningkatan pada tahun 2012 dibandingkan tahun 2011.

Kabupaten Kudus merupakan salah satu daerah dengan industri manufaktur berskala Nasional, khususnya untuk komoditas rokok. ${ }^{4}$ Tidak mengherankan jika Kota Kudus dikenal sebagai Kota Kretek. Tembakau merupakan bahan baku dalam pembuatan rokok. Debu tembakau dalam proses pemotongan maupun produksi rokok bisa menganggu kesehatan. Wanita hamil yang bekerja di pabrik rokok berpotensi terkena nikotin rokok karena intensif berhubungan dengan tembakau hampir setiap hari.Efek negatif dari nikotin yaituyang berpengaruh terhadap derajat kesehatan seseorang adalah perilaku. Seorang ibu sangat berperan penting dalam pengasuhan anak sehingga perilaku ibu akan berpengaruh terhadap kesehatan anaknya.

Tujuan penelitian ini adalah untuk menganalisis hubungan pekerjaan di Pabrik Rokok dan Perilaku Hidup Bersih Sehat (PHBS) terhadap kematian bayi di Kabupaten Kudus. mengganggu perkembangan plasenta dan fungsinya dalam mentransfer oksigen ke janin yang dapat berdampak pada gangguan pertumbuhan janin, BBLR, prematuritas, dan peningkatan kematian bayi. ${ }^{5}$ Salah satu faktor

\section{Metode}

Rancangan penelitian yang digunakan adalah analitik komparatif dengan pendekatan kasus kntrol yaitu pengambilan data dimulai dari kejadian kematian bayi. Kelompok kasus adalah ibu yang bayinya meninggal pada tahun 2012 dan kelompok kontrol adalah ibu yang melahirkan bayi pada tahun 2012 dan sudah berulang tahun pada saat dilakukan penelitian. Penelitian ini dilakukan di Kabupaten Kudus.

Populasi dalam penelitian ini adalah semua ibu di Kecamatan Kaliwungu, Kecamatan Jekulo, Kecamatan Undaan, dan Kecamatan Gebog yang bayinya meninggal pada tahun 2012 yaitu sebanyak $70 \mathrm{ibu}$. Sampel kasus sebanyak $70 \mathrm{ibu}$ yang bayinya meninggal. Sampel kontrol dengan perbandingan 1:1 sebanyak 70 ibu yang memiliki bayi hidup dan sudah berulang tahun pada saat dilakukan penelitian.

Teknik pengambilan sampel untuk kelompok kasus menggunakan total sampling sedangkan untuk kelompok kontrol dilakukan dengan memilih kelompok kasus dan kontrol dari populasi yang sama. Rancangan analisis bivariabel menggunakan chi-kuadrat

\section{Hasil}

\section{Tabel 1 Karakteristik demografi ibu}

\begin{tabular}{|c|c|c|c|c|}
\hline \multirow[t]{2}{*}{$\begin{array}{l}\text { Karakteristik } \\
\text { demografi ibu }\end{array}$} & \multicolumn{2}{|c|}{$\begin{array}{l}\text { Kelompok } \\
\text { kasus }\end{array}$} & \multicolumn{2}{|c|}{$\begin{array}{c}\text { Kelompok } \\
\text { kontrol }\end{array}$} \\
\hline & $\mathrm{n}$ & $\%$ & $\mathrm{n}$ & $\%$ \\
\hline \multicolumn{5}{|l|}{ 1. Usia melahirkan } \\
\hline$<20$ tahun & 2 & 3,3 & 2 & 3,3 \\
\hline 20-35 tahun & 49 & 81,7 & 49 & 81,7 \\
\hline$\geq 35$ tahun & 9 & 15 & 9 & 15 \\
\hline \multicolumn{5}{|l|}{ 2. $\bar{P}$ aritas ibu } \\
\hline 1 kali & 21 & 35 & 31 & 51,7 \\
\hline 2-4 kali & 36 & 60 & 29 & 48,3 \\
\hline$>4$ kali & 3 & 5 & 0 & 0 \\
\hline \multicolumn{5}{|l|}{$\begin{array}{l}\text { 3. Jarak kelahiran } \\
\text { anak }\end{array}$} \\
\hline$<2$ tahun & 25 & 41,7 & 31 & 51,7 \\
\hline$\geq 2$ tahun & 35 & 58,3 & 29 & 48,3 \\
\hline
\end{tabular}

Pada tabel ini, menunjukkan bahwa mayoritas usia ibu saat melahirkan adalah 20-35 tahun $(81,7 \%)$ pada masing-masing kelompok. Mayoritas paritas ibu pada kelompok kasus adalah 2-4 kali (60\%) sedangkan pada kelompok kontrol adalah 1 kali $(51,7 \%)$. Mayoritas jarak kelahiran anak pada kelompok kasus adalah $\geq 2$ tahun $(58,3 \%)$ sedangkan pada kelompok kontrol adalah $<2$ tahun $(51,7 \%)$. 
Lailatul Mustaghfiroh : Hubungan Pekerjaan Di Pabrik Rokok dan Perilaku Hidup Bersih Sehat Ibu Terhadap Kematian Bayi

Hubungan pekerjaan di Pabrik Rokok dan sikap ibu mengenai PHBS terhadap kematian bayi

Tabel 2 Hubungan pekerjaan di Pabrik Rokok dan sikap PHBS ibu pada kelompok kasus dan kelompok kontrol

\begin{tabular}{|c|c|c|c|c|c|c|}
\hline \multirow[t]{2}{*}{ Variabel } & \multicolumn{3}{|c|}{ Kelompok kasus } & \multirow{2}{*}{$\begin{array}{c}\text { Kelompok } \\
\text { kontrol } \\
\%\end{array}$} & \multirow[t]{2}{*}{ Nilai $\mathrm{p}^{*}$} & \multirow{2}{*}{ OR (IK 95\%) } \\
\hline & $\mathrm{n}$ & $\%$ & $\mathrm{n}$ & & & \\
\hline \multicolumn{7}{|l|}{ 1. Pekerjaan ibu } \\
\hline Pekerja pabrik rokok & 18 & 30 & 14 & 23 & 0,409 & $1,408(0,624-3,178)$ \\
\hline Bukan pekerja pabrik rokok & 42 & 70 & 46 & 77 & & \\
\hline \multicolumn{7}{|l|}{ 2. Sikap PHBS ibu } \\
\hline Negatif & 32 & 53 & 28 & 47 & 0,465 & $1,306(0,637-2,676)$ \\
\hline Positif & 28 & 47 & 32 & 53 & & \\
\hline
\end{tabular}

Keterangan : ${ }^{*}$ berdasarkan uji chi kuadrat

Pada tabel 2 ini, menunjukkan tidak terdapat hubungan bermakna antara pekerjaan di Pabrik
Rokok dan sikap ibu mengenai PHBS terhadap kematian bayi $(\mathrm{p}>0,05)$.

Tabel 3 Interaksi pekerjaan di Pabrik Rokok dan sikap PHBS ibu terhadap kematian bayi

\begin{tabular}{lcccc}
\hline \multicolumn{1}{c}{ Interaksi variable } & \multicolumn{2}{c}{ Kelompok } & Nilai & OR (IK 95\%) \\
\hline $\begin{array}{l}\text { Ibu pekerja pabrik rokok dan sikap negatif } \\
\text { mengenai PHBS }\end{array}$ & 10 & 10 & 0,381 & $1,40(0,43-4,53)$ \\
$\begin{array}{l}\text { Ibu pekerja pabrik rokok dan sikap positif } \\
\text { mengenai PHBS }\end{array}$ & 8 & 4 & & $2,80(0,64-13,07)$ \\
$\begin{array}{l}\text { Ibu bukan pekerja pabrik rokok dan sikap } \\
\text { negatif mengenai PHBS }\end{array}$ & 22 & 18 & $1,71(0,67-4,37)$ \\
$\begin{array}{l}\text { Ibu bukan pekerja pabrik rokok dan sikap } \\
\text { positif mengenai PHBS }\end{array}$ & 20 & 28 & 1,00 \\
\hline
\end{tabular}

Pada tabel 3 menunjukkan bahwa variabel yang paling dominan berpengaruh terhadap kematian bayi adalah ibu yang bekerja di Pabrik Rokok dan memiliki sikap positif mengenai PHBS dengan nilai OR 2,80 artinya ibu yang bekerja di Pabrik Rokok dan memiliki sikap yang positif mengenai PHBS memiliki risiko untuk terjadinya kematian bayi sebesar 2,80 kali lebih besar dibandingkan ibu dengan kondisi yang lain. Sementara itu nilai PARnya 64,29 artinya apabila faktor risiko (berupa ibu yang bekerja di Pabrik Rokok dan memiliki sikap positif mengenai PHBS) dihilangkan maka bersifat protektif terhadap kematian bayi sebesar $64,29 \%$.

\section{Pembahasan}

Dua pertiga dari bayi yang meninggal terjadi pada masa neonatal (bulan pertama kehidupannya). ${ }^{6}$ Derajat kesehatan neonatal sangat terkait dengan kesehatan ibu semasa kehamilan, pertolongan persalinan, dan perawatan bayi baru lahir. Kematian neonatal (28 hari pertama) paling lazim disebabkan oleh kejadian pranatal (faktor-faktor yang dibawa anak sejak lahir yang diperoleh dari orang tuanya pada saat konsepsi) dan kejadian tepat setelah lahir/selama proses persalinan. Sementara itu, kematian pascaneonatal (antara 28-365 hari) lebih dipengaruhi oleh lingkungan bayi, yang mencakup antara lain keterampilan orangtua dan ketersediaan serta pemanfaatan layanan pediatrik. $^{3,7,8}$

Tabel 2 menunjukkan tidak terdapat hubungan bermakna pekerjaan di Pabrik Rokok terhadap kematian bayi. Dengan demikian meskipun setiap hari ibu terpapar oleh tembakau, baik yang belum diolah maupun yang sudah diolah, dan kemungkinan partikel nikotin dari tembakau akan terhirup oleh ibu, namun ternyata tidak berpengaruh terhadap kondisi kesehatan ibu dan janin. Tabel 2 juga menunjukkan tidak terdapat hubungan bermakna PHBS ibu terhadap 
kematian bayi disebabkan selain sikap ibu sebagai faktor predisposisi, perilaku juga dipengaruhi oleh ketersediaan sumber-sumber/ fasilitas yang ada sebagai faktor yang mendukung, serta sikap dan perilaku petugas dan toma sebagai faktor yang memperkuat atau mendorong.

Tabel 3 menunjukkan faktor yang paling dominan terhadap kematian bayi adalah interaksi antara pekerjaan di Pabrik Rokok dan sikap ibu yang positif mengenai PHBS terhadap kematian bayi sebesar 2,80. Apabila faktor risiko (berupa ibu bekerja di Pabrik Rokok dan memiliki sikap yang positif mengenai PHBS tersebut dihilangkan maka bersifat protektif terhadap kematian bayi sebesar 64,29\%. Hal ini menunjukkan bahwa walaupun ibu memiliki sikap yang positif mengenai PHBS, namun jika ibu hamil terpapar oleh nikotin tembakau maka dapat memengaruhi kondisi janin intrauterine.Ibu dapat melahirkan BBLR atau asfiksia neonatorum akibat terjadi gangguan pertumbuhan janin dan hipoksia janin di dalam kandungan disebabkan adanya gangguan perkembangan plasenta dan fungsinya dalam mentransfer oksigen ke janin.

\section{Simpulan}

Berdasarkan hasil penelitian dapat disimpulkan bahwa tidak terdapat hubungan pekerjaan di Pabrik Rokok dan PHBS ibu terhadap kematian bayi. Ibu yang bekerja di Pabrik Rokok dan memiliki sikap positif mengenai PHBS merupakan faktor risiko terjadinya Bayi Berat Lahir Rendah (BBLR), asfiksia neonatorum, kelainan kongeital, infeksi, dan diare sebagai penyebab langsung kematian bayi.

\section{Daftar Pustaka}

1. Dube L, Taha M, Asefa $H$. Determinants of Infant Mortality in Community of Gilgel Gibe Field Research Center, Southwest Ethiopia: a Matched Case Control Study. BioMed Central Public Health. 2013;13(401):1-8.

2. Survey Demografi dan Kesehatan Indonesia 2012 Laporan Pendahuluan. Jakarta: Badan Pusat Statistik, Badan Kependudukan dan Keluarga Berencana Nasional, Kementerian Kesehatan, MEASURE DHS; 2012.

3. Wandira AK, Indawati R. Faktor Penyebab Kematian Bayi Di Kabupaten Sidoarjo. Jurnal Biometrika dan Kependudukan. 2012;1:33-42.

4. Kudus dalam Angka 2012/2013. Badan Perencanaan Pembangunan Daerah Kabupaten Kudus dan Badan Pusat Statistik Kabupaten Kudus.

5. Wahabi HA, Alzeidan RA, Fayed AA, Mandil A, Al-Shaikh G, Esmaeil SA. Effects of secondhand smoke on the birth weight of term infants and the demographic profile of Saudi exposed women. BioMed Central Public Health. 2013;13(341):1-6.

6. Djaja S, Soemantri S. Penyebab Kematian Bayi Baru Lahir (Neonatal) dan sistem pelayanan Kesehatan yang Berkaitan di Indonesia Survei Kesehatan Rumah Tangga (SKRT) 2001. Buletin Penelitian Kesehatan. 2003;31:155-65.

7. Rahmawati T, L T, N H. Pola Penyakit Penyebab Kematian Bayi di Pedesaan dan Perkotaan, Kondisi Sosio Ekonomi pada Kejadian Kematian Bayi di Indonesia Hasil Riskesdas 2007. Bulletin Penelitian Sistem Kesehatan. 2011;14:108-14.

8. Mekonnen Y, Tensou B, Telake DS, degefie T, Bekele A. Neonatal Mortality in Ethiopia: trends and Determinants. BioMed Central Public Health 2013;13(483):1-14. 
Lailatul Mustaghfiroh : Hubungan Pekerjaan Di Pabrik Rokok dan Perilaku Hidup Bersih Sehat Ibu Terhadap Kematian Bayi 